Vol. 8, N. 2, Year 2016

ISSN: 2037-0830 - DOI: 10.1515/rem-2016-0019

\title{
Virtual realities and education
}

\author{
Igor D.D. Curcio ${ }^{\mathrm{a}}$, Anna Dipace ${ }^{\mathrm{b}}$, Anita Norlund ${ }^{\mathrm{c}}$ \\ ${ }^{a}$ Nokia Technologies, Tampere, Finland, Email: igor.curcio@nokia.com, ORCID 0000-0002-2234-933X \\ ${ }^{b}$ University of Foggia, Foggia, Italy, Email: anna.dipace@unifg.it, ORCID 0000-0001-9826-073X \\ ${ }^{c}$ University of Borås, Borås, Sweden, Email: anita.norlund@hb.se, ORCID 0000-0003-1681-5418
}

\begin{abstract}
The purpose of this paper is to highlight the state-of-the-art of virtual reality, augmented reality mixed reality technologies, and their applications in formal education. We also present a selected list of case studies that prove the utility of these technologies in the context of formal education. Furthermore, as byproduct, the mentioned case studies show also that, although the industry is able to develop very advanced virtual environments technologies, their pedagogical implications are strongly related to a well designed theoretical framework.
\end{abstract}

Keywords: virtual reality; augmented reality; mixed reality; formal education; learning affordances.

\section{Introduction}

In the last decade, the research community has devoted special attention to the use of new technologies in education. This paper attempts to bring two worlds into a unique perspective. On one side, virtual reality with its technology peculiarities. On the other side, formal educational environments. The use of Virtual Reality (VR), Augmented Reality (AR) and Mixed Reality (MR) in educational environments is becoming increasingly popular in the recent years. Particularly, in such contexts Virtual Reality Leaning Environments (VRLEs) are interactive learning environments that favor the immersion and allow to simulate a realistic environment in which users can perform specific tasks. In the design of VRLEs it is becoming essential to refer to pedagogical theories that can enhance effective learning. The following section 1 gives an introduction to the recent technology developments in the areas of VR, AR and MR with particular emphasis on conceptual definitions, history, current state of the art, and challenges. Section 2 focuses the application of these technologies in formal education, whereas section 3 reviews some case studies retrieved in the recent literature with the purpose of showing the efficacy of these technologies in promoting learning and their learning affordances. Final considerations and conclusions end the paper.

\section{Technologies}

\subsection{Virtual reality}

According to a simplified definition in (Wikipedia, 2016), VR replicates an environment that simulates the physical presence in places in the real or imaginary world, allowing users to interact in that world. The replication of an environment is achieved by the creation (through specialized hardware and software) of artificial experiences that involve several senses. For instance, sight, hearing, touch, and in some cases also smell. These define also the possible interaction modalities. VR experiences can be visually rendered on computer screens and TVs. However, a deeper feeling of immersion can be obtained using Head Mounted Displays (HMDs), which are devices that allow stereoscopic vision within a full 360-degree environment. Examples of such displays include the Oculus Rift or the Samsung Gear VR devices. The hearing component can be added to a visual VR experience through the use of VR speakers or headphones that can provide spatial audio; this include the possibility of hearing a sound from the direction where it is generated within the VR scene. A way to increase interactivity in a virtual world is through the use of touch. This 
typically happens with an ordinary computer keyboard, or a mouse or through more advanced interfaces such as wired gloves that allow the transmission of tactile information, for example for gaming or medical or military applications. The replicated environment can be similar to the real world (e.g., in a classroom lesson, in a geography documentary or in a music concert), or different from the real world (e.g., in VR games that make use of synthetic graphic content).

The concept related to virtual reality is not new. Its first occurrence is dated back the year 1932 when the English writer Aldous Huxley published the book Brave New World where he described the feelies as movies that reach your senses with sight, hearing and touch (Huxley, 1932). Few years later, in 1939, the View-Master, a stereoscopic display of color photos on film was introduced to the market and produced for a period of 70 years. While the VR technology has been used in the military field since 1966, the first experimental VR HMD is due to Ivan Sutherland in the year 1968 (Sutherland, 1965). However, this device was quite primitive in terms of user interface and so heavy that it had to be suspended from the ceiling in order to be worn. In 1977, a virtual simulation of the city of Aspen in Colorado was created by MIT. It allowed to go virtually around the city during different simulated seasons. In 1991, Sega produced a game-oriented headset with LCD screen, stereo headphones and an inertial sensor to track the user's head and react to its movements. After several decades of experimenting VR in limited environments, this became accessible to the mass market thanks to the Google Cardboard in the year 2014. This is a do-it-yourself HMD for smartphones priced at around 15 dollars. The technology developments were not only on the display side but, among the others, also on the capture side. A variety of 360-degree recording cameras have been introduced to the market in the last period for allowing VR content to be easily produced. These range from relatively inexpensive consumer cameras, such as the LG $360 \mathrm{CAM}$, which includes two cameras, up to professional cameras, such as the Nokia OZO, which incorporates 8 highresolution cameras and 8 microphones for spatial 3D sound, to be used for high-quality studio content productions.

Despite virtual reality has been researched for over half century, there are still today some concerns on the usage of this technology. In fact, several products come with consumer warnings because their prolonged usage may cause health-related side effects, such as motion sickness, disorientation and loss of balance (Lawson, 2014). These are caused by the head motion while wearing a HMD and are the effect of high latencies, low picture display rates and high pixel persistence. Latency is essentially the time it takes between head motion and the refresh of the displayed picture corresponding to the new head position (motion-to-photon delay). It is dependent on hardware processing power and, in some cases, also on transmission network delays. Latencies longer than few hundred milliseconds are not optimal in a VR system (Draper et al., 2001). Picture display rates are related to motion smoothness. In VR, picture display rates below 75 pictures per second yield a sub-optimal viewing experience (Oculus, 2016). Picture display rates depend on hardware processing power and network bandwidth availability. Pixel persistence is the time a pixel remais lit. A pixel persistence longer than 3ms produces motion blurring (Wikipedia, 2016). A HMD has also a limited Field of View $(F o V)$, which is typically in the order of 90-100 degrees, while humans have typically a FoV of 220-320 degrees (Abrash, 2016). Another VR challenge is given by the pixel density. Currently, the state-of-the-art technology offers about 15 pixels per degree (ppd), while humans with perfect vision can reach 120 ppd (Abrash, 2016). This data shows that there is a long way to reach a level of VR vision comparable to that of humans. High pictures display rates, displayed FoV and pixel density all contribute to a large volume of data to be processed. This imposes new requirements on transmission networks and hardware processing capabilities. To decrease the data volume, new video compression algorithms are needed. Data volume reduction could also be achieved by taking full advantage of foveated rendering (Abrash, 2016), which is a mechanism that uses the properties of the human visual system, for which humans perceive as sharp the object(s) watched directly (i.e., that fall on the fovea of the human eye), while the surroundings are seen more blurred. Recent technology developments are quite promising, and it is likely that the health side effects produced by the current technologies will disappear during this or next decade.

\subsection{Augmented reality}

A live view of a physical, real world environment whose elements are augmented by sound, graphics and digital sensor data can be defined as augmented reality (Wikipedia, 2016). In AR, the view of the reality is modified by a computer program. Here the technology is helping to enhance the view of the real world by overlaying information on the top of it. The information can be real (such as weather data) or virtual (such as computer graphics characters like in the Pokemon Go game). While VR is a rather stationary form of experience with little mobility, AR is inherently a mobile experience.

Conceptually, AR was initially conceived in 1901 by the author L. Frank Baum who mentioned the idea of electronic spectacles that overlay data on the top of real life. However, the term augmented reality was first used in 1990 by T.P. Caudell, a former Boeing researcher. Baum's idea has been studied and researched for decades, until 2013 when Google announced a developer version of the AR Glasses which are capable of capturing the world and project it on the eyeglass surface in augmented view with objects from the physical and virtual world. The lightweight $36 \mathrm{~g}$ hardware included an optical HMD, a Bluetooth interface to receive Internet connectivity via a mobile phone. Interaction with the glasses happens through voice, touch or via head motion. The AR Glasses are also capable of projecting images and 


\section{Virtual realities and education \\ Curcio, Dipace, Norlund}

record video and still pictures. In 2015 Microsoft announces a developer version of the Hololens AR headset. This device weights over half $\mathrm{kg}$ and incorporates several environment understanding cameras, among other things.

The main hardware elements for AR are: processor, display, sensors, input devices. Typical AR devices include mobile phones and tablets. However, these have the disadvantage that users need to hold these devices in front of them all the time. Displays could be HMDs, eyeglasses, bionic contact lenses (Greenemeier, 2011), among the others. Sensors are used for tracking the position and orientation of the user in the 3D space at a given point of time. Some of the most used sensors for AR are camera, microphone, accelerometer, GPS, compass, gyroscope, RFID. The most used input devices in AR include speech and gesture recognition systems, motion sensors, gloves, pointer, etc.

Perhaps one of the first AR applications in education is in textbooks. Here special embedded markers, when scanned by an AR device, provide additional information to the student. Another useful application of AR is the visualization of parts of the body directly on the human body: a feature which is useful to students of schools of medicine, for example. Section 2 of this paper contains further applications of AR in education.

As in VR, also for AR there exist concerns on the usage of this technology. The most relevant, apart the technological challenges which are mostly similar to those related to VR, is related to privacy. The main issue is that AR devices are becoming very powerful and capable of analyzing the environment in real time. Even in public places there might be areas where a certain privacy should be guaranteed. Also, recording copyrighted material could also be a legal issue. Furthermore, real-time face recognition algorithms could easily break the privacy of an individual. Imagine the case of a user wearing AR glasses in a shopping center: for any face encountered, the AR system could easily provide information about social media, pictures, marital status, criminal record and so on (Roesner et al., 2014).

\subsection{Mixed reality}

The last section of this paper related to technology is about mixed reality. This can be defined as the merging of real and virtual worlds to produce new environments where physical and virtual objects co-exist and interact in real time (Wikipedia, 2016). If we consider a virtuality continuum, MR takes place anywhere between reality and virtual reality (Milgram \& Kishino, 1994) as shown in Figure 1.

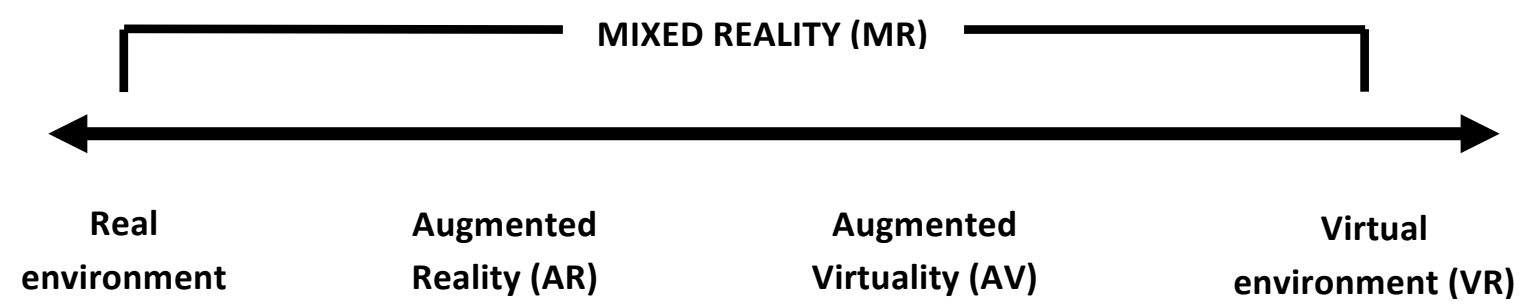

Fig. 1 Reality-Virtuality continuum.

In this sense, depending on the degree of reality or virtuality in the environment, the positioning of MR would be more towards the left side or the right side of the continuum. For instance, with AR virtual objects augment the reality, whereas with Augmented Virtuality $(A V)$ real objects augment the virtual reality. The basic technologies and concerns already described for VR and AR in the previous sections apply also to MR. Applications in education that make use of $\mathrm{MR}$, as well as VR and AR technologies, will be the subject of the following section.

\section{Virtual environments in education: applications}

Applications in education may refer to a variety of aspects such as selection, organization and assessment (Young, 1998). This section will deal with these aspects alongside the question of which common educational fields or school subjects have primarily been the object of applications. Specific examples will also be given.

\subsection{Virtual reality in education}

Educational research on VR was initially conducted in the area of sciences (Roussou, Oliver \& Slater, 2006), an area that still seems to hold a firm grip. Here, astronomy, earth rotation and related concepts make up one topic, as for instance in the Desktop VR Earth Motion Systems DVREMS (Chen et al., 2007). A further VR study within the science area addresses 'motion' and 'forces' through Dr. Friction, a multiplayer educational gaming application (Annetta et al., 2009). In a so-called protein game with 3D avatars, biology and biomolecules as well as proteins and amino acids constitute yet another science focus (Cai et al., 2006), as well as VR-ENGAGE (Virvou \& Katsionis, 2008, p. 161) where the subject of geography gets attention. Another group of studies relate to arithmetic. Here we find Virtual 
Playground and the exploration of students' understanding of fractions (Roussou, Oliver \& Slater, 2006). Related to this, is a Collaborative Virtual Reality Learning Environment (CVRLE) study paying particular attention to geometry and, for example, the calculation of volume (Hwang \& Hu, 2013).

VR environments seem to be less commonly used or researched in the area of social studies and history. However, we found one in the context of World War II, where students took part in an activity combining the classroom and the D-Day museum via the technology Myartspace (Vavoula et al., 2009). An emphasis on societal issues (sometimes closely related to moral aspects) was in like manner found in the study (Falloon, 2010) of an avatar-based presentation and storytelling tool where the aspects summarised are 'such things as street safety, fighting ethnic prejudice, eliminating tagging, reducing pollution' (p. 117). Actually, quite a few studies refer to a type of multi-perspective possibilities. River City, which is a VR game mentioned occasionally in previous literature, connects to "realistic, historical, sociological, and geographical conditions" (Psotka, 2013, p. 72). Psotka contributes with this more specific scenario:

"I imagine allowing children to experience and explore the conceptual universe of atomic and chemical structures; an unspoiled ecosystem; historical reenactments; the plays of Shakespeare, just as concretely as they now explore their playrooms and backyards" (p. 76).

The goal of informing students about the benefits of Quest Atlantis in "the context of important social issues and aesthetically-rich dramatic play" (Gerstein, 2009, p. 4) shows that also the subject of arts has gained attention.

Previous research indicate that VR contents are regularly combined with more traditional material. In a specific example on the use of the MARWIN tool, the following was included:

“...text to speech functionality (including textual thinking and speech 'balloons'); a variety of character gestures, movements, and animated sequences; and a library of graphical backgrounds: images and music” (Falloon, 2010, p. 112).

Often the technology-based activities are framed as a problem to solve, as to "find the book of wisdom, which is hidden" (Virvou \& Katsionis, 2008, p. 158). In essence, feedback turns out being given to students in the form of rewards; badges (Kamarainen et al., 2013), money to shop clothes, etc. (i.e., in the currency connected to the introduced game) (Gerstein, 2009), keys (Virvou \& Katsionis, 2008), or a sign and sound when the given answers are not correct (Yang, Chen \& Jeng, 2010).

\subsection{Augmented reality in education}

Just as is the case of VR, educational research on AR is mainly placed within the context of science. Here, astronomy, earth rotation and related concepts make up one topic (Kerawalla et al., 2006) and "understanding and interpretation of water quality measurements" another, as when mobile wireless devices and the AR technology FreshAir was applied in combination with environmental probeware (Kamarainen et al., 2013, p. 545). Also related to the natural sciences is the AR game Alien Contact, reported to be possibly used in connection to education on "different current events (energy crisis, oil shortage, global nuclear threat, cultural differences)" (Dunleavy, Dede \& Mitchell, 2009 , p. 11) or in order "to study an outbreak of whooping cough" (p. 9).

Arts should likewise be mentioned as having been the subject of applications of AR. The purpose of using the AR technology Popcode was to inform students about Italian Renaissance art (Di Serio, Ibáñez \& Kloos, 2013). Also here, the researchers combined a variety of material:

“...virtual things (such as texts, images, videos, 3D models, animation) were fused with real objects (such as chair, map, guitar)" (p. 1085).

Yet another example of combining new and traditional material (see above) refers to the AR game The Table Mystery used in the subject of chemistry (the "team" in the quote relates to the test team):

"Each team was given an iPad mini, a chemistry book and a notebook. The teams also had access to a PC to search for chemistry-related answers" (Boletsis \& McCallum, 2013, p. 91).

It becomes evident that the integration of the technologies in focus of this paper has encouraged a variety of location choices. For instance, the ordinary classroom has been combined with field trips and the use of AR in order to enhance the students' knowledge of ecosystem science (Kamarainen et al., 2013).

Previous research has paid attention to the well-known and, possibly problematic, border between game and education. We can see the endeavours to cross this border: the AR environment Alien Contact was developed by researchers in order to be similar to entertaining games such as Halo 3 (Microsoft), Alien vs. Predator, etc. (Dunleavy, Dede \& Mitchell, 2009, p. 9). The mentioned authors pinpoint that there are good opportunities "if the tools are coupled with sound pedagogy to teach meaningful skills" (p. 18).

A typical activity when any of the three reality types in this paper is applied has the character of a hunt, puzzle or a problem to solve. This is a representative example from the AR area, collected from the Alien Contact: 


\section{Virtual realities and education \\ Curcio, Dipace, Norlund}

“...aliens have landed on earth and seem to be preparing for a number of alternative actions, including peaceful contact, invasion, plundering, or simply returning to their home planet the goal is to find out why the aliens have landed"

(Dunleavy, Dede \& Mitchell, 2009, p.10).

Some arrangements represent the so-called jigsaw pedagogy as where the students were given different roles, and only by collaborating they were able to reach the expected conclusion (Dunleavy, Dede \& Mitchell, 2009). Another example refers to distributed roles and knowledge (Boletsis \& McCallum, 2013). Here, the students were given rewards in the form of new, desirable codes.

\subsection{Mixed reality in education}

As far as educational research on MR environments is concerned, we find, again, studies within the area of science: the technology of Situated Multimedia Arts Learning Lab (SMALLab) was applied in earth science education (Birchfield \& Megowan-Romanowicz, 2009). However, educational MR research can also be found within language education. A specific example refers the use of RoboStage including the robot Scribbler, and to phraseology and vocabulary development within the area of food ordering in a restaurant or purchasing of concert tickets (Chang et al., 2010). Within the human sciences, we also find learning about the history of Amsterdam through the game Frequency 1550 (de Souza e Silva \& Delacruz, 2006). In yet another study, the purpose was to make students familiar with multimodality and meaning-making by letting them design a virtual museum and, in connection, develop critical, multimodal awareness (Ho et al., 2011).

The descriptions of learning activities connected to the applications at hand are often complex and lengthy. Thus, we chose to give only one example here within an MR environment, i.e., SMALLab, which was mentioned above. It focuses on the evolution from a geological perspective:

"This action will insert the layer into the layer cake structure at the level that corresponds with the current time period. A
second glowball is used to grab a fossil from among ten options and drop into the structure. This action embeds the fossil in
the current sediment layer. On the east side of the display, students see an interactive clock with geologic time advancing to
increment each new period" (Birchfield \& Megowan-Romanowicz, 2009, p. 410).

As already mentioned, the integration of technologies has encouraged a variety of location. Such an example of MR environments is found within the context of Frequency 1550 where half of the class stayed in the classroom, while the other half went to the city (de Souza e Silva \& Delacruz, 2006).

There are several illustrations within the reality environments in the form of facilitating chat functions and encouraging students to discuss during the learning process. Yet another way is to use large displays, and thus, a combination of "both one-to-one screen experiences and whole-class MR collaboration" as in connection to the MEteor simulation game on how asteroids move (Lindgren \& Johnson-Glenberg, 2013, p. 450). Just like in connection to VR and AR, competition is a salient feedback feature when it comes to MR. For example, students are encouraged to win by annexing the largest part of the city of Amsterdam (de Souza e Silva \& Delacruz, 2006) in the MR game (hybrid reality, $\mathrm{HR}$, in the authors' denomination) Frequency 1550.

\section{Virtual environments in education: case studies}

\subsection{Case studies on VR}

There are many case studies that demonstrate the effectiveness of usage of VR learning in formal education contexts. In her review of game-based learning "Learning in Immersive worlds", Sara de Freitas (2006), presents many case studies describing examples of games as learning experiences. Most of them present VR environments that can be utilized in education, and they are the result of a dialogue between academia and industry. For instance, Hazmat: Hotzone is a programme developed by the Entertainment Technology Centre of Carnegie-Mellon University, produced in conjunction with the New York City Fire Department. Many educational stakeholders recognise the great potential of 3D simulations, games and virtual environments in the field of education in order to promote engagement, exploration, manipulation, representation of ideas (Dalgarno \& Lee, 2010). According to de Freitas (2006), Dalgarno \& Lee:

"much time, financial and other resources are therefore being devoted to efforts aimed at harnessing the pedagogic potential of these technologies, with academia, industry and government working to develop new platforms, tools and resources to support these endeavours" (p. 11).

Huang et al. (2010) describe two case studies in order to show

"that interaction is a crucial factor to affect learning performance" (p. 9). 


\section{Virtual realities and education}

Curcio, Dipace, Norlund

In both the analysed case studies they describe VR systems designed for medical students. In the first one they present a Web-based 3D VR interactive learning system designed to examine in depth the structure of human body. The research conducted aimed to investigate two main hypotheses based on immersion, interaction, imagination and it focused on the analysis of the increase in motivation (H1) and problem-solving capabilities (H2). After one month of using the VR system, 190 students were interviewed via a questionnaire composed by 16 questions based on a constructive theoretical approach in order to investigate learners' attitudes toward the VR learning environment. As for the first hypothesis (H1), the results showed that out of the three critical factors (intuitive interactions, the sense of physical imagination, the feeling of immersion), the latter is the one that contributes more than the other two on increasing motivation after using VR. As for the second hypothesis (H2), since the authors used a predicted model as statistical method, the results showed that interaction had more prediction than the other two critical factors.

In the second case study, they present a collaborative learning environment named 3D Human Organ Learning System (3D-HOLS). This is a system that gives multiple students the opportunity to interact, practice and discuss in a virtual space. In this case study the authors examine the same three critical factors as in the previous case; however, here they investigate its possible positive effects on collaborative learning. More specifically, the authors define two hypotheses by using the 3D-HOLS System. The first one is linked to the correlation between the three critical factors and the positive effects on collaborative learning. The second relates to the positive correlation between collaborative learning and behavioural intention of using 3D-HOLS system. The sample was composed by 76 students interviewed through a 25-question questionnaire. The results of this research showed that, as for the first hypothesis, all three factors were predictors for the collaborative learning, and imagination in a particular way. As for the second hypothesis, results showed that collaborative learning provides $59 \%$ of contributions for students' intention to use the VR learning system.

The above two case studies seem to confirm the learning affordances of 3D virtual learning environments identified by Dalgarno \& Lee (2010, p. 10):

"the facilitation of tasks that lead to enhanced spatial knowledge representation, greater opportunities for experiential learning, increased motivation/engagement, improved contextualisation of learning and richer/more effective collaborative learning as compared to tasks made possible by 2-D alternatives".

\subsection{Case studies on $A R$}

As for the VR, many educational researchers (Dunleavy et al., 2009; Cheng et al., 2013, Ibáñez et al., 2014; Perry, 2015; Villarán et al., 2015; Yilmaz, 2016) recognise the great potential of AR in promoting benefits in terms of achieved learning. Furthermore, there are studies (Dünser et al., 2006; Gutiérrez et al., Dalgarno \& Lee, 2010) that explore the learning affordances offered by using AR.

In the study conducted by María Blanca Ibáñez and her colleagues (2014, p. 1), the authors assess an AR application to learn the basic concepts of electromagnetism. The research questions they tried to answer with their research were about the state of flow, the challenge-skill perception, the learning outcomes, the perceived benefits and difficulties of using an AR application to learn the mentioned discipline. More specifically, the authors conducted a research by investigating the use of AR with $12^{\text {th }}$ grade students enrolled in four Spanish schools. Here, the sample was made of 64 high school students, out of which only 60 students were considered, because four students didn't complete some of the tests. The main objective of this study was on understanding the level of enjoyment of the students involved. The authors compared the experimental group made by students that used AR technology against a control group made of students that used similar Web-based lesson which encompassed identical learning objectives and content. The design of both applications provided the same information and workflow capabilities.

As for the overall flow state achieved, the results of the study showed that the students involved in the experimental group were more likely to experience positive moods when following the learning activities than the control group students. Furthermore, the achievement of deep learning in the experimental group students was related to their higher level of concentration on the task and on their distorted sense of time.

As for the challenge-skill perception, no statistically significant difference between the two groups was found. The study gathered results about the students' perception about skills and challenge through a two-question evaluation performed at the end of every learning stage. The authors noticed that:

"flow imbalances among the learning stages were found to be mainly associated with the perceived difficulty of the content and the form of interaction with the application" (p.12).

As for the learning effectiveness, results of this case study confirm previous researches about improvements in academic achievements compared to traditional teaching methods when using AR technologies (a list of these researches is available in p. 12 of the study by Ibáñez et al., 2014). In particular, in this case study, the results showed that 


\section{Virtual realities and education}

Curcio, Dipace, Norlund

"students who used the AR application performed significantly better on knowledge than those who were taught using the web- based application" (p.12).

Another case study that allows understanding how AR is capable of affect learning experiences is the gamified system Explorez (Perry, 2015). It is the first place-based game directed towards the acquisition of French language skills. Explorez allows learning to take place outside of the classroom in order to offer a meaningful and immersive learning experience for the participants. The game design includes avatars, missions, and it creates the feelings of anticipation, open-end missions, badges and fast feedback. Thanks to all these features, students described the experience as "fun"; in fact, some of them played longer than the class lasted in order to finish their missions.

Even though the mentioned study is still at a preliminary stage, it seems to demonstrate the potential of gamifying French-language learning by means of quest-based learning and ARs. These preliminary results help to consider Explorez as an extra tool to take the students outside the classroom for creating a more authentic experience to enhance critical-thinking, problem-solving, teamwork and increase motivation.

\subsection{Case studies on $M R$}

As for VR and AR technologies, the application of MR simulation in the field of education is very much investigated by many researchers (Arnab et al., 2011; Johnson-Glenberg et al., 2014; Hoffmann et al., 2014; Lindren et al., 2016).

A study conducted by Lindgren and colleagues (2016) investigates the consequences of a whole-body MR simulation game on science learning outcomes with a comparison between an experimental group and a control group were participants used the same simulation game on a desktop computer. The sample was composed by 113 seventh grade students (12-13 years old) from three schools. In a university laboratory, the participants were randomly assigned to an experimetal group or to a control group. The former group used the whole-body version of simulation, while the latter group used a desktop version of it. The study was about gravity and planetary motion in an immersive, wholebody interactive simulation. The results included a comparison of students learning and attitudes about science on students of the two groups. The study showed that "enacting concepts and experiencing critical ideas in physics through whole-body activity leads to significant learning gains, higher levels of engagement, and more positive attitudes towards science" (p. 174). The simulation influences the affordances of MR environments to enact ideas and receive multisensory and physical feedback on these ideas (Tscholl \& Lindgren, 2016).

The effectiveness of MR to improve science learning compared to regular classroom instruction is demonstrated by two studies conducted by Johnson-Glenberg and colleagues (2014). Specifically, the authors explore the types of learning gains that can be expected when students learn in an Embodied Mixed REality Learning Environment (EMRELE). An example of this special environment that makes use of motion-capture and a highly collaborative pedagogy is the already mentioned SMALLab. Two case studies were analysed: ths first one about the chemistry titration, and the second one about disease transmission. Results showed that placement of a student in the embodied EMRELE condition consistently led to greater learning gains, compared to ordinary instruction methods.

\section{Conclusions}

The paper tries to shed light on the use of VR, AR and MR technologies in the field of education. There is some evidence that these new technologies and their applications in education can contribute to increase, among the others, motivation, engagement and critical thinking in students, and positively support knowledge transfer. The current challenges are on the design of theoretical guidelines and/or instructional principles that could assist educators in developing and applying virtual learning environments correctly. Actually, in literature it is possible to find some efforts that lead to this direction. An example is the "four dimensional framework" offered by de Freitas \& Oliver (2006). It is a sort of "guide" that can be used by teachers, tutors, game designers in order to evaluate the potential of using games- and simulation-based learning during their practices, and sustain more critical approaches to this form of games and simulations. The authors consider four important dimensions to evaluate games and simulation: context; learner specification; pedagogic considerations; mode of representation. Even though this model has been designed specifically for games and simulations, because of its connection with pedagogical issues, it is possible to consider it useful even for educational virtual reality environments. The technologies also seem to facilitate multi-perspectivity and creative combinations of material (new and traditional), of locations (inside and outside school), and of time (travelling in history). Alongside the many motivational affordances highlighted, a critical eye could be needed concerning the heavy reliance on hunts and rewards. First, it might be that every topic is not suitable for competitive arrangements and, second, there is a risk that participants could suffer from a 'competition fatigue'. Yet another challenge is the present dominance of the field of (natural) sciences, calling for applications also in other fields such as social sciences, in which the technologies are underused. 


\section{Virtual realities and education}

Curcio, Dipace, Norlund

\section{References}

Abrash, M. (2016). Oculus Connect 3 opening keynote. Retrieved from https://www.youtube.com/watch?v=AtyE5qOB4gw.

Annetta, L., Mangrum, J., Holmes, S., Collazo, K. \& Meng-Tzu, C. (2009). Bridging realty [sic] to virtual reality: Investigating gender effect and student engagement on learning through video game play in an elementary school classroom. International Journal of Science Education, 31(8), 1091-1113.

Arnab, S., Petridis, P., Dunwell, I., \& de Freitas, S. (2011). Enhancing learning in distributed virtual worlds through touch: a browser-based architecture for haptic interaction. In Serious Games and Edutainment Applications (pp. 149-167). Springer, London.

Birchfield, D. \& Megowan-Romanowicz, C. (2009). Earth science learning in SMALLab: A design experiment for mixed reality. Computer-Supported Collaborative Learning, 4(4),403-421.

Boletsis, C. \& McCallum, S. (2013). The table mystery: An augmented reality collaborative game for Chemistry education. In (Eds.) M. Minhua, M. F. Oliveira, S. Petersen \& J. Baalsrud Hauge. Proceedings of Serious Games Development and Applications: 4th International Conference, Trondheim, Norway, September 25-27, 2013, (pp. 8695).

Cai, Y., Lu, B., Zheng, J. \& Li, L. (2006). Immersive protein gaming for bio edutainment. Simulation \& Gaming, 37(4), 466-475.

Chang, C-W., Lee, J-H., Wang, C-Y. \& Chen, G-D. (2010). Improving the authentic learning experience by integrating robots into the mixed-reality environment. Computers \& Education, 55(4), 1572-1578.

Chen, C. H., Yang, J. C., Shen, S., \& Jeng, M. C. (2007). A desktop virtual reality earth motion system in astronomy education. Educational Technology \& Society, 10(3), 289-304.

Cheng, K. H., \& Tsai, C. C. (2013). Affordances of augmented reality in science learning: Suggestions for future research. Journal of Science Education and Technology, 22(4), 449-462.

Dalgarno, B., \& Lee, M. J. W. (2010). What are the learning affordances of 3-D virtual environments? British Journal of Educational Technology, 41(1), 10-32.

de Freitas, S. (2006). Learning in immersive worlds. London: Joint Information Systems Committee.

de Freitas, S., \& Oliver, M. (2006). How can exploratory learning with games and simulations within the curriculum be most effectively evaluated?. Computers \& education, 46(3), 249-264.

De Souza e Silva, A. (2006). Re-Conceptualizing the Mobile Phone--From Telephone to Collective Interfaces. Australian Journal of Emerging Technologies \& Society, 4(2).

Di Serio, Ibáñez \& Kloos, (2013). Impact of an augmented reality system on students' motivation. Computers \& Education, 68, 586-596.

Draper, M.H., Viire, E.S., Furness, T.A. \& Gawron V.J. (2001). Effects of image scale and systems time delay on simulator sickness within head-coupled virtual environments. Human Factors, 43(1), 129-146.

Dunleavy, M., Dede, C. \& Mitchell, R. (2009). Affordances and limitations of immersive participatory augmented reality simulations for teaching and learning. Journal of Science Education and Technology, 18(1), 7-22.

Dünser, A., Steinbügl, K., Kaufmann, H., \& Glück, J. (2006). Virtual and augmented reality as spatial ability training tools. In Proceedings of the seventh ACM SIGCHI international conference on computer-human interaction, (pp. 125-132).

e Silva, A. D. S., \& Delacruz, G. C. (2006). Hybrid reality games reframed potential uses in educational contexts. Games and Culture, 1(3), 231-251.

Falloon, G. (2010). Using avatars and virtual environments in learning: What do they have to offer? British Journal of Educational Technology, 41(1), 108-122.

Gerstein, J. (2009). Beyond the game: Quest Atlantis as an online learning experience for gifted elementary students. Journal of Virtual Worlds Research, 2(1), 2-18.

Greenemeier, L. (2011). Computerized Contact Lenses Could Enable In-Eye Augmented Reality. Scientific American (online) retrieved from http://blogs. scientificamerican. com/observations/computerized-contact-lenses-couldenable-in-eye-augmented-reality/ (accessed on 23rd March 2016).

Gutiérrez, M. J., Saorín, J. L., Contero, M., Alcañiz, M., López, P. D. C., \& Ortega, M. (2010). Design and validation of an augmented book for spatial abilities development in engineering students. Computers \& Graphics, 34(1), 77-91.

Ho, C. M., Nelson, M. E., \& Müeller-Wittig, W. (2011). Design and implementation of a student-generated virtual museum in a language curriculum to enhance collaborative multimodal meaning-making. Computers \& Education, 57(1), 1083-1097.

Hoffmann, M., Meisen, T., \& Jeschke, S. (2014). Shifting Virtual Reality Education to the Next Level-Experiencing Remote Laboratories through Mixed Reality. In Proceedings of the International Conference on Computer Science, Computer Engineering, and Education Technologies, Kuala Lumpur, Malaysia.

Huang, H. M., Rauch, U., \& Liaw, S. S. (2010). Investigating learners' attitudes toward virtual reality learning environments: Based on a constructivist approach. Computers \& Education, 55(3), 1171-1182.

Huxley, A. (1932). Brave new world. Chatto \& Windus.

Hwang, W.-Y. \& Hu, S.-S. (2013). Analysis of peer learning behaviors using multiple representations in virtual reality and their impacts on geometry solving problems. Computers \& Education, 62, 308-319. 
Ibáñez, M. B., Di Serio, Á., Villarán, D., \& Kloos, C. D. (2014). Experimenting with electromagnetism using augmented reality: Impact on flow student experience and educational effectiveness. Computers \& Education, 71, 113.

Johnson-Glenberg, M. C., Birchfield, D. A., Tolentino, L., \& Koziupa, T. (2014). Collaborative embodied learning in mixed reality motion-capture environments: Two science studies. Journal of Educational Psychology, 106(1), 86.

Kamarainen, A. M., Metcalf, S., Grotzer, T., Browne, A., Mazzuca, D., , M. S. \& Dede, C. (2013). EcoMOBILE: Integrating augmented reality and probeware with environmental education field trips. Computers \& Education, 68, 545-556.

Kerawalla, L, Luckin, R., Seljeflot, S. \& Woolard, A. (2006). "Making it real": exploring the potential of augmented reality for teaching primary school science. Virtual Reality, 10(3),163-174.

Lawson, B. D. (2014). Motion sickness symptomatology and origins. Handbook of virtual environments: Design, implementation, and applications, 531-599.

Lindgren, R. \& Johnson-Glenberg, M. (2013). Emboldened by embodiment: Six precepts for research on embodied learning and mixed reality. Educational Researcher, 42(8), 445-452.

Lindgren, R., Tscholl, M., Wang, S., \& Johnson, E. (2016). Enhancing learning and engagement through embodied interaction within a mixed reality simulation. Computers \& Education, 95, 174-187.

Milgram, P., \& Kishino, F. (1994). A taxonomy of mixed reality visual displays. IEICE Transactions on Information and Systems, 77(12), 1321-1329.

Oculus (2016). Oculus best practices. Retrieved from https://developer3.oculus.com/documentation/intro$\mathrm{vr} /$ latest/concepts/bp_app_rendering/.

Perry, B. (2015). Gamifying French language learning: a case study examining a quest-based, Augmented Reality mobile learning-tool. Procedia-Social and Behavioral Sciences, 174, 2308-2315.

Psotka, J. (2013). Educational Games and Virtual Reality as Disruptive Technologies. Educational Technology \& Society, 16(2), 69-80.

Roesner, F., Denning, T., Newell, B. C., Kohno, T., \& Calo, R. (2014, September). Augmented reality: hard problems of law and policy. In Proceedings of the 2014 ACM International Joint Conference on Pervasive and Ubiquitous Computing: Adjunct Publication (pp. 1283-1288). ACM.

Roussou, M., Oliver M, \& Slater, M. (2006). The virtual playground: an educational virtual reality environment for evaluating interactivity and conceptual learning. Virtual Reality, 10(3), 227-240.

Sutherland, I.E. (1965). The ultimate display. Proceedings of the IFIP 65 Congress, Vol. 2. (pp. 506-508).

Tscholl, M., \& Lindgren, R. (2016). Designing for Learning Conversations: How Parents Support Children's Science Learning Within an Immersive Simulation. Science Education.

Vavoula, G., Sharples, M., Rudman, P., Meek, J. \& Lonsdale, P. (2009). Myartspace: Design and evaluation of support for learning with multimedia phones between classrooms and museums. Computers \& Education, 53(2), $286-299$.

Villarán, D., Ibáñez, M. B., \& Kloos, C. D. (2015). Augmented Reality-Based Simulations Embedded in Problem Based Learning Courses. In Design for Teaching and Learning in a Networked World (pp. 540-543). Springer International Publishing.

Virvou, M. \& Katsionis, G. (2008). On the usability and likeability of virtual reality games for education: The case of VR-ENGAGE. Computers \& Education, 50(1), 154-178.

Wikipedia (2016). Augmented reality, Retrieved from https://en.wikipedia.org/wiki/Augmented_reality.

Wikipedia (2016). Mixed reality, Retrieved from https://en.wikipedia.org/wiki/Mixed_reality.

Wikipedia (2016). Virtual reality, Retrieved from https://en.wikipedia.org/wiki/Virtual_reality.

Yang, J. C., Chen, C. H. \& Jeng, M. C. (2010). Integrating video-capture virtual reality technology into a physically interactive learning environment for English learning. Computers \& Education, 55(3), 1346-1356.

Yilmaz, R. M. (2016). Educational magic toys developed with augmented reality technology for early childhood education. Computers in Human Behavior, 54, 240-248.

Young, M.F.D. (1998). The Curriculum of the Future: From the "New Sociology of Education" to a Critical Theory of Learning. London, Falmer Press. 